\title{
Microsatellite Instability in Intraductal Papillary Neoplasms of the Biliary Tract
}

Susan C. Abraham, M.D., Jae-Hyuk Lee, M.D., Ph.D., John K. Boitnott, M.D., Pedram Argani, M.D., Emma E. Furth, M.D., Tsung-Teh Wu, M.D., Ph.D.

Division of Gastrointestinal/Liver Pathology, Department of Pathology, The Johns Hopkins University School of Medicine, Baltimore, Maryland (SCA, JKB, PA); Department of Pathology and Laboratory

Medicine, University of Pennsylvania School of Medicine, Philadelphia, Pennsylvania (EEF); and

Department of Pathology, University of Texas M.D. Anderson Cancer Center (JHL, TTW), Houston, Texas

Intraductal papillary neoplasms of the biliary tree are unusual lesions characterized by solitary or diffuse growth along the intra- and/or extrahepatic biliary tract. Biliary papillary neoplasms bear some clinicopathologic similarity to intraductal papillary mucinous neoplasms of the pancreas. Like intraductal papillary mucinous neoplasms of the pancreas, biliary papillary neoplasms can be purely intraductal lesions or can give rise to invasive adenocarcinomas. We recently studied the genetic alterations present in a series of biliary papillary neoplasms and noted the presence of allelic shifts in some biliary tumors during allelic loss assays on chromosomes $5 \mathrm{q}$ and $18 \mathrm{q}$. This suggested that microsatellite instability might play a role in the molecular pathogenesis of biliary papillary neoplasms. Genomic DNA was extracted from 17 intraductal papillary neoplasms, 6 associated invasive cholangiocarcinomas, and corresponding normal tissues, and microsatellite instability testing was performed using the 5 microsatellite loci recommended by the 1997 National Cancer Institute-sponsored consensus conference (D2S123, D5S346, D17S250, Bat-25, and Bat-26). High-level microsatellite instability was considered to be present when at least two of five microsatellite loci showed allelic shifts, and low-level microsatellite instability, when only one locus was shifted, as per the National Cancer Institute criteria. We also determined the methylation status of the DNA mismatch repair gene hMLH1 by bisulfite treatment of genomic DNA, followed by methylation-specific PCR. High-level microsatellite instability was present in 2 of $17(11.8 \%)$ biliary

Copyright () 2002 by The United States and Canadian Academy of Pathology, Inc.

VOL. 15, NO. 12, P. 1309, 2002 Printed in the U.S.A.

Date of acceptance: September 4, 2002.

Address reprint requests to: Susan C. Abraham, M.D., Department of

Pathology, Hilton 11, Mayo Clinic, 220 First Street SW, Rochester, MN

55905; e-mail: abraham.susan@mayo.edu; fax: 507-284-1599.

DOI: 10.1097/01.MP.0000038461.80167.34 papillary neoplasms, including 1 case of purely intraductal tumor and 1 case with both intraductal and invasive cholangiocarcinoma components. In both cases there was extensive microsatellite instability, with allelic shifts in five of five and four of five microsatellite markers, respectively. Low-level microsatellite instability was present in 6 of $17(35.3 \%)$ biliary papillary neoplasms, including 2 cases of purely intraductal tumor and 4 cases with both intraductal and invasive cholangiocarcinoma components. Interestingly, the pattern of allelic shifts was frequently not identical between the intraductal and invasive cholangiocarcinoma components; although the same microsatellite markers were shifted, alleles of differing lengths were generated in the intraductal and invasive components of the neoplasms with high-level microsatellite instability and of two neoplasms with low-level microsatellite instability. None of the biliary papillary neoplasms ( 0 of 10 cases with adequate DNA for evaluation) showed methylation of $h M L H 1$. These results indicate that microsatellite instability is a relatively frequent event in papillary neoplasms of the biliary tree but is not associated with $h M L H 1$ promoter hypermethylation. The finding that alleles of differing lengths were frequently generated between the intraductal and invasive components of those tumors with microsatellite instability suggests that there is significant genetic heterogeneity within these neoplasms.

KEY WORDS: Biliary papillomatosis, Biliary tract, Cholangiocarcinoma, Microsatellite instability.

Mod Pathol 2002;15(12):1309-1317

Papillary tumors derived from biliary epithelium are unusual neoplasms that can arise in the intraand/or extrahepatic bile ducts and can either remain localized or spread extensively along the biliary tree. The World Health Organization (WHO) recognizes both benign (e.g., biliary papillomatosis, 
biliary intraepithelial neoplasia/dysplasia) and malignant (papillary cholangiocarcinoma) forms (1). Biliary papillomatosis has been described extensively (2-16) despite its relative rarity because of its dramatic presentation: diffusely dilated bile ducts filled with delicate papillary excrescences that can result in mechanical obstruction, ascending cholangitis, and death, even when the neoplasm itself is purely intraductal (7). Other intraductal papillary neoplasms have also been described that are not classified by the WHO, including localized papillary epithelial proliferations that are termed papillary adenomas or papillomas (17) and villous adenomas (18) and more diffuse papillary epithelial proliferations that are sometimes termed mucinhypersecreting bile duct tumors (19).

With the relatively recent description of pancreatic intraductal papillary mucinous neoplasms (pancreatic IPMNs) has come increasing recognition that there exists a distinctive subset of these biliary papillary neoplasms bearing some similarity to pancreatic IPMNs with respect to radiologic features, biologic behavior, and histologic appearance (19-22). In particular, these lesions arise within the bile ducts and in all cases demonstrate a predominant component of intraductal growth. Like pancreatic IPMNs, however, they can give rise to invasive cholangiocarcinomas $(4,6,19,20,22-25)$ and therefore are considered to represent neoplasms of low-grade malignant potential. Architecturally, these neoplasms, like pancreatic IPMNs, are defined by their growth as papillary fronds containing fine vascular cores (22). The neoplastic epithelial cells themselves are often of biliary type but can also show gastric or intestinal differentiation, including the presence of goblet cells and Paneth cells (22). Finally, like pancreatic IPMNs, many of these distinctive biliary papillary neoplasms show overproduction of extracellular intraductal mucin. This is not a universal feature, however; in a recent large study of intraductal papillary neoplasms of the liver, Shimonishi et al. (22) reported that only 39 of 66 (59\%) cases showed mucin overproduction.

The genetic alterations that contribute to the neoplastic progression of these distinctive biliary papillary neoplasms have only rarely been investigated. One case of biliary papillomatosis arising in association with a congenital choledochal cyst was found to carry an activating mutation in the K-ras oncogene (11). Shimonishi et al. (22) found that nuclear expression of p53 correlated with progression of intraductal papillary neoplasms of the liver. We recently studied the genetic alterations in a series of biliary papillary neoplasms and their associated invasive cholangiocarcinomas and found relatively low frequencies of $\mathrm{K}$-ras gene mutations, nuclear $\beta$-catenin protein accumulation, and allelic loss on chromosomes $18 \mathrm{q}$ and $5 q$ (20). During those investigations, we noted allelic shifts among several of the biliary papillary neoplasms using microsatellite markers for allelic loss analysis, although these were not the microsatellite markers recommended by the National Cancer Institute (NCI) for formal evaluation of microsatellite instability (MSI; 26). Nevertheless, this suggested that MSI might play a role in the molecular pathogenesis of a subset of these tumors.

The purpose of this study was therefore to formally investigate microsatellite instability in biliary papillary neoplasms. We evaluated a series of 17 biliary papillary neoplasms (selected based on their histologic similarity to pancreatic IPMNs) and 6 associated invasive cholangiocarcinomas for microsatellite instability using the NCI criteria and evaluated the methylation status of the human Mut L homologue ( $h M L H 1)$ gene promotor, one of the key DNA mismatch repair genes.

\section{MATERIALS AND METHODS}

\section{Case Selection and Histologic Classification}

The study population consisted of 17 patients with biliary papillary neoplasms of the intraand/or extrahepatic biliary tract, including 15 patients who underwent biopsy or resection at The Johns Hopkins Hospital between 1985 and 2001 and 2 patients who underwent resection at the University of Pennsylvania Medical Center in 1999 and 2000. All neoplasms located in the distal common bile duct or ampullary region were excluded from the study to avoid overlap with ampullary carcinomas and pancreatic IPMNs. Clinical and pathologic data, including age, gender, location of tumor, and type of surgical procedure, were obtained from the computerized patient files and from the surgical pathology files.

These cases were selected during histologic review of a larger set of biliary tumors in which the term papillary had been used in the diagnostic report. Criteria for inclusion included predominant intraductal growth within dilated bile ducts, an architectural pattern of fine papillary fronds with vascular cores, and an overall impression during review that the tumor histologically resembled a pancreatic IPMN. The cases were further classified as showing either localized or extensive growth (intraductal papillary growth in multiple intra- and/or extrahepatic bile ducts). Those tumors with extensive intraductal growth constituted the majority of cases $(n=15)$ in this study. However, we also included cases of localized growth $(n=2)$ that otherwise histologically resembled pancreatic IPMNs, because pancreatic IPMNs can be either solitary or extensively involve the pancreatic duct system (27). Because no established criteria for grading dysplasia 
within these distinctive biliary neoplasms have been published, we graded the epithelial dysplasia within the biliary IPNs according to WHO criteria for pancreatic IPMNs (28). Briefly, these were classified based on the highest degree of dysplasia as intraductal papillary adenomas if they showed columnar epithelial cells with little to no cytologic atypia, a low nuclear to cytoplasmic ratio with abundant cytoplasm, and little nuclear pseudostratification; as intraductal papillary borderline neoplasms if they showed mild to moderate nuclear atypia and hyperchromatism as well as nuclear pseudostratification that was limited to the basal two thirds of the epithelium; and as intraductal papillary carcinomas if they showed severe cytologic atypia, loss of nuclear polarity, or architectural cribriforming or papillary fusion (29). Cases with both intraductal papillary tumor and invasive adenocarcinoma were classified as intraductal papillary neoplasms with associated invasive cholangiocarcinoma.

\section{DNA Extraction}

Microdissection of H\&E-stained slides for DNA extraction was performed from formalin-fixed, paraffin-embedded specimens. For most cases, we dissected an area of $\sim 0.5-1 \mathrm{~cm}^{2}$ from a $5-\mu \mathrm{m}$ section into $100 \mu \mathrm{L}$ of digestion buffer, although the exact number of neoplastic cells varied with the cellularity of the tumor, the size of the neoplastic cells, and the abundance of extracellular mucin and/or matrix material. Genomic DNA was extracted as described previously (30). Tissue corresponding to the intraductal papillary tumor was microdissected in all 17 cases, and in 6 cases, associated invasive cholangiocarcinoma was also microdissected. Normal control DNA was extracted from non-neoplastic liver parenchyma (13 cases), nonneoplastic periductal connective tissue (2 cases), benign lymph node (1 case), or normal colonic biopsy (1 case).

\section{Microsatellite Instability Analysis}

MSI testing was performed using the five microsatellite loci (D2S123, D5S346, D17S250, Bat-25, and Bat-26) recommended by the 1997 National Cancer Institute (NCI)-sponsored consensus conference (26). Primer sequences are given in Table 1. Assays were performed by fluorescent-labeled polymerase chain reaction (PCR) amplification using fluorescent dye-labeled forward primer and unlabeled reverse primer. The forward primer was endlabel with 6-FAM (Applied Biosystems, Foster City, CA). PCR amplification was performed in $15-\mu \mathrm{L}$ reaction volumes containing $1 \mu \mathrm{L}$ of genomic DNA, $9 \mu \mathrm{L}$ of ABI Prism True Allele PCR Premix (Applied Biosystems), 5 pmol of 6-FAM-labeled forward
TABLE 1. Microsatellite Loci and Primer Sequences for Microsatellite Instability Analysis

\begin{tabular}{lc}
\hline Microsatellite Locus (Label): Primer Sequence & Product Size (bp) \\
\hline D2S123 (Fam) & $197-227$ \\
Forward: 5'-AAACAGGATGCCTGCCTTTA-3' & \\
Reverse: 5' -GGACTTTCCACCTATGGGAC-3' & $96-122$ \\
D5S346 (Fam) & \\
Forward: 5'-ACTCACTCTAGTGATAAATCGGG-3' & \\
Reverse: 5'-AGCAGATAAGACAGTATTACTAGTT-3' & $151-169$ \\
D17S250 (Fam) & \\
Forward: 5'-GGAAGAATCAAATAGACAAT-3' & \\
Reverse: 5' -GCTGGCCATATATATATTTAAACC-3' & \\
Bat-25 (Fam) & 116 \\
Forward: 5'-TCGCCTCCAAGAATGTAAGT-3' \\
Reverse: 5' -TCTGCATTTTAACTATGGCTC-3' \\
Bat-26 (Fam) \\
Forward: 5'-TGACTACTTTTGACTTCAGCC-3' \\
$\quad$ Reverse: 5' -AACCATTCAACATTTTTAACCC-3' \\
\hline
\end{tabular}

primer, and 10 pmol of unlabeled reverse primer. The following cycling conditions were used for all PCR reactions: denaturation at $95^{\circ} \mathrm{C}$ for 6 minutes; 45 cycles of $94^{\circ} \mathrm{C}$ for 45 seconds, $55^{\circ} \mathrm{C}$ for 45 seconds, and $72^{\circ} \mathrm{C}$ for 1 minute; and a final extension at $72^{\circ} \mathrm{C}$ for 30 minutes. The PCR products were diluted with $30 \mu \mathrm{L}$ of $\mathrm{H}_{2} \mathrm{O}$, and a $1.0-\mu \mathrm{L}$ aliquot of each diluted fluorescent-labeled PCR product was combined with $12 \mu \mathrm{L}$ of formamide and $0.5 \mu \mathrm{L}$ of GeneScan 400HD (ROX) size standard (Applied Biosystems). The samples were then capillary electrophoresed on an ABI 3700 DNA Analyzer and analyzed using GeneScan Analysis software (Applied Biosystems).

Chromatograms were interpreted according to the criteria described in detail by Berg et al. (31). High-level microsatellite instability (MSI-high) was considered to be the case when at least two of five microsatellite loci showed shifting; low-level microsatellite instability (MSI-low), when only one locus was shifted; and microsatellite stable, when none of the loci were shifted, as per the NCI criteria (26).

\section{Methylation Status of hMLH1}

The methylation status of $h M L H 1$ was determined by bisulfite treatment of genomic DNA, followed by methylation-specific PCR, as previously described, with modification (32). Briefly, $2 \mu \mathrm{g}$ of microdissected genomic DNA was denatured with $2 \mathrm{M} \mathrm{NaOH}$ at $37^{\circ} \mathrm{C}$ for 10 minutes, followed by incubation with $3 \mathrm{~m}$ sodium bisulfite ( $\mathrm{pH} 5.0$ ) at $50^{\circ} \mathrm{C}$ for 16 hours in the dark. After treatment, the DNA was purified using a DNA cleanup kit as recommended by the manufacturer (Promega, Madison, WI), incubated with $3 \mathrm{M}$ $\mathrm{NaOH}$ at room temperature for 5 minutes, precipitated with $10 \mathrm{~m}$ ammonium acetate and $100 \%$ ethanol, washed with $70 \%$ ethanol, and finally resuspended in $20 \mu \mathrm{L}$ of distilled water. $h M L H 1$ methylation status for each sample was determined by using $2 \mu \mathrm{L}$ of bisulfite-treated DNA as the template 
for PCR reactions using primers specific for methylated and unmethylated alleles. Primer sequences for the unmethylated reaction were as follows: 5'AGAGTGGATAGTGATTTTTAATGT-3' (forward) and 5' - ACTCTATAAATTACTAAATCTCTTCA-3' (reverse), and for the methylated reaction they were as follows: 5'-GATAGCGATTTTTAACGC-3' (forward) and 5'TCTATAAATTACTAAATCTCTTCG-3' (reverse). Amplification was carried out in a GeneAmp PCR System 9700 thermocycler (Perkin Elmer, USA) with 40 cycles of $95^{\circ} \mathrm{C}$ for 30 seconds, $53^{\circ} \mathrm{C}$ for 45 seconds, and $72^{\circ}$ $\mathrm{C}$ for 30 seconds, followed by a final extension at $72^{\circ}$ $\mathrm{C}$ for 4 minutes. Ten-microliter aliquots of the PCR products were electrophoresed on $5 \%$ acrylamide gels and visualized by ethidium bromide staining. DNA from the RKO colon cancer cell line (American Type Culture Collection, Manassas, VA) was used as a control for methylation.

\section{RESULTS}

A summary of the clinicopathologic and molecular findings in the 17 biliary papillary neoplasms (designated B1 to B17) is presented in Table 2.

\section{Clinicopathologic Characteristics}

All were tumors of adult patients ranging from 39 to 81 years (mean, 63.4 y). There was a slight predominance of women, with 10 (59\%) women and 7 $(41 \%)$ men. The biliary papillary neoplasms involved only the intrahepatic biliary tree in 7 (41\%) patients, only the extrahepatic biliary tree (exclusive of distal common bile duct and ampullary neoplasms) in 5 (29\%) patients, and both intrahepatic and extrahepatic ducts in $5(29 \%)$ patients. In one case, histologic classification was performed on biopsy material only (Case B1), whereas in the remaining cases, complete evaluation of the tumors was possible based on surgical resection specimens (including liver explant in two patients).

Fifteen of 17 biliary papillary neoplasms showed extensive growth within the biliary tree, and two were solitary tumors. Histopathologically, the intraductal component in the majority of the tumors (16 of $17,94 \%$ ) was graded as intraductal papillary carcinoma (Fig. 1A-B), and in 7 cases (41\%), the biliary intraductal papillary carcinoma was associated with an infiltrating cholangiocarcinoma (only 6 cholangiocarcinomas were microdissected and analyzed for MSI status because of marked stromal contamination in one infiltrating tumor, Case B17). Associated infiltrating cholangiocarcinomas were all of ordinary tubular type (Fig. 1C), and no example of colloid-type carcinoma was present. Only one biliary papillary neoplasm was graded as intraductal papillary adenoma, and this case (B13) was not associated with invasive cholangiocarcinoma.

Microsatellite Instability and hMLH1 Methylation

High-level microsatellite instability (MSI-high) was present in 2 (11.8\%) neoplasms (Cases B15 and B16). In Case B15, a purely intraductal neoplasm, there was

TABLE 2. Clinicopathologic Characteristics and Microsatellite Instability in Biliary Papillary Neoplasms

\begin{tabular}{|c|c|c|c|c|c|c|c|}
\hline Case & Age (y)/Sex & Location & Pattern of Growth & Histology & MSI Status & Markers Shifted & hMLH1 Methylation \\
\hline B1 & $61 / \mathrm{M}$ & EHD & localized & IPC & MSI-low & D5S346 & N/A \\
\hline B2 & $79 / F$ & IHD & extensive & IPC & MSI-low & D2S123 & N/A \\
\hline B3 & $69 / F$ & IHD & extensive & IPC & stable & - & unmethylated \\
\hline B4 & $76 / F$ & IHD & extensive & IPC & stable & - & unmethylated \\
\hline B5 & $39 / F$ & IHD & localized & IPC & stable & - & N/A \\
\hline \multirow[t]{2}{*}{ B6 } & $49 / \mathrm{F}$ & EHD+IHD & extensive & IPC & MSI-low & D5S346 & N/A \\
\hline & & & & invasive & MSI-low & D5S346 & N/A \\
\hline B7 & $53 / \mathrm{M}$ & IHD & extensive & IPC & stable & - & unmethylated \\
\hline \multirow[t]{2}{*}{ B8 } & $74 / \mathrm{F}$ & IHD & extensive & IPC & MSI-low & D17S250 & unmethylated \\
\hline & & & & invasive & MSI-low & D17S250 & unmethylated \\
\hline B9 & $75 / \mathrm{M}$ & EHD & extensive & IPC & stable & - & N/A \\
\hline B10 & $67 / F$ & EHD & extensive & IPC & stable & - & unmethylated \\
\hline \multirow[t]{2}{*}{$\mathrm{B} 11^{\mathrm{a}}$} & $65 / \mathrm{M}$ & EHD+IHD & extensive & IPC & MSI-low & D17S250 & N/A \\
\hline & & & & invasive & MSI-low & D17S250 & N/A \\
\hline \multirow[t]{2}{*}{$\mathrm{B} 12^{\mathrm{a}}$} & $64 / \mathrm{M}$ & EHD & extensive & IPC & MSI-low & D2S123 & N/A \\
\hline & & & & invasive & MSI-low & D2S123 & N/A \\
\hline B13 & $50 / \mathrm{F}$ & EHD+IHD & extensive & IPA & stable & - & unmethylated \\
\hline \multirow[t]{2}{*}{ B14 } & $54 / F$ & EHD+IHD & extensive & IPC & stable & - & unmethylated \\
\hline & & & & invasive & stable & - & unmethylated \\
\hline B15 & $65 / \mathrm{M}$ & IHD & extensive & IPC & MSI-high & $\begin{array}{l}\text { D5S346, D17S250, D2S123, } \\
\text { Bat-25, Bat-26 }\end{array}$ & unmethylated \\
\hline \multirow[t]{2}{*}{$\mathrm{B} 16^{\mathrm{a}}$} & $57 / \mathrm{M}$ & EHD+IHD & extensive & IPC & MSI-high & $\begin{array}{l}\text { D5S346, D17S250, D2S123, } \\
\text { Bat-26 }\end{array}$ & unmethylated \\
\hline & & & & invasive & MSI-high & $\begin{array}{l}\text { D5S346, D17S250, D2S123, } \\
\text { Bat-25, Bat-26 }\end{array}$ & N/A \\
\hline B17 & $81 / F$ & EHD & extensive & IPC & stable & - & unmethylated \\
\hline
\end{tabular}

EHD, extrahepatic biliary tree; IHD, intrahepatic biliary tree; IPA, intraductal papillary adenoma; IPC, intraductal papillary carcinoma; MSI, microsatellite instability; N/A, insufficient DNA for evaluation or reaction failed (Case B16-invasive).

${ }^{a}$ For Cases B11, B12, and B16, the length of the newly generated alleles differed between the intraductal and invasive components. 

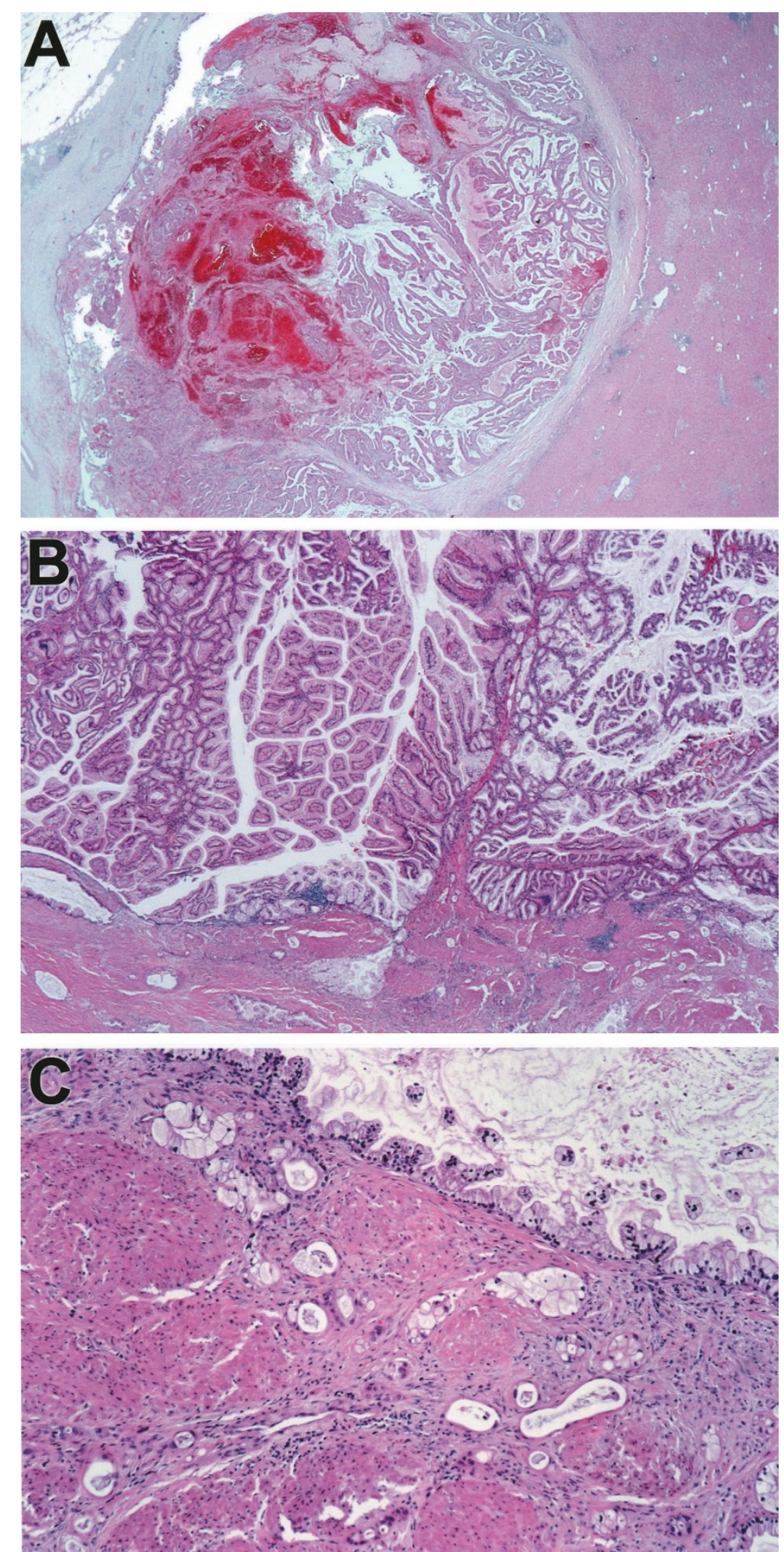

FIGURE 1. Histologic appearance of biliary papillary neoplasms. A, intraductal papillary carcinoma filling a dilated bile duct within the liver (hematoxylin and eosin stain; original magnification, $20 \times$ ). B, intraductal papillary carcinoma with abundant luminal mucin, here located within a dilated cystic duct (hematoxylin and eosin stain; original magnification $60 \times$ ). C, underlying invasive carcinoma of tubular type is present within the wall of the duct from (B) (hematoxylin and eosin stain; original magnification, $200 \times$ ). extensive MSI, with shifting observed in all five NCIrecommended microsatellite loci. In Case B16, both the intraductal papillary carcinoma and its associated invasive cholangiocarcinoma showed MSI-high. Interestingly, however, only four loci were shifted in this biliary intraductal papillary carcinoma (D2S123,
D5S346, D17S250, and Bat-26), whereas Bat-25 was also shifted in the cholangiocarcinoma. In addition, for each common shifted locus (D2S123, D5S346, D17S250, and Bat-26) the amplicon length also differed between the intraductal and cholangiocarcinoma components (Fig. 2). 


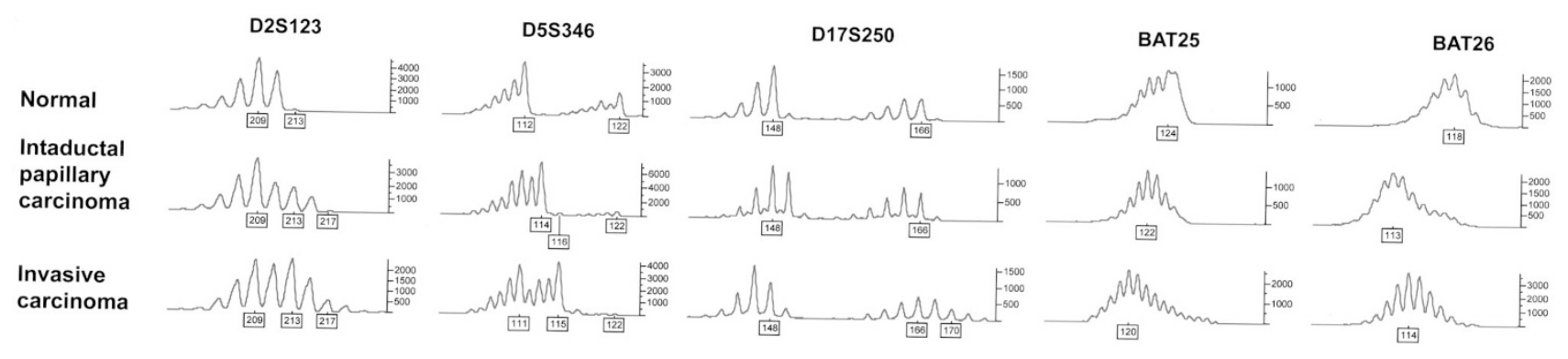

FIGURE 2. High-level microsatellite instability in Case B16. Allelic shifts in D2S123, D5S346, D17S250, and Bat-26 are present in the intraductal papillary carcinoma component, whereas the associated invasive cholangiocarcinoma also shows shifting in Bat-25. The shifting pattern for D17S250 and Bat-25 is subtle, but even if these markers are discounted, criteria for high-level microsatellite instability are met. In addition, the amplicon lengths of the shifted alleles differ between the intraductal and invasive carcinoma components of this neoplasm.

Low-level microsatellite instability (MSI-low) was present in $6(35.3 \%)$ neoplasms (Cases B1, B2, B6, B8, B11, and B12; Fig. 3). Cases B1 and B2 contained intraductal biliary papillary carcinoma only. Cases B6 and B8 contained both intraductal and invasive cholangiocarcinoma components, and in these cases both the intraductal tumors and their associated cholangiocarcinomas demonstrated shifts in the same markers and generation of identical amplicon lengths. Cases B11 and B12 also contained both intraductal and invasive cholangiocarcinoma components with shifting of the same locus, but in these cases the intraductal biliary papillary neoplasms and their associated cholangiocarcinomas generated differing amplicon lengths.

There was no significant tendency for those biliary papillary neoplasms with MSI to be located preferentially in the intra- or extrahepatic biliary tree; of the 8 biliary tumors with MSI, 2 involved the extrahepatic ducts exclusively, 3 the intrahepatic ducts exclusively, and 3 involved both the intraand extrahepatic ducts. The remaining 9 (53\%) neoplasms were microsatellite stable. Evaluation for hypermethylation of the $h M L H 1$ promoter was possible in 10 cases for which adequate DNA was present, and no methylation was detected in any of these 10 biliary papillary neoplasms (including the 2 cases with MSI-high) or 2 associated cholangiocarcinomas (Fig. 4).

\section{DISCUSSION}

Intraductal papillary neoplasms of the biliary tree are uncommon neoplasms, and little is known re-

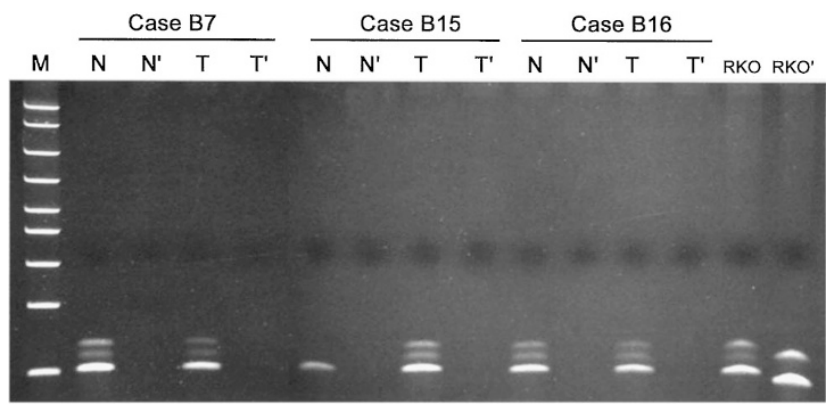

FIGURE 4. Lack of $h M L H 1$ promoter region hypermethylation in Cases B7 (microsatellite- stable), B15 (high-level MSI), and B16 (highlevel MSI). In each case the DNA fails to amplify using methylationspecific primers (denoted by \&vprime;) but amplifies with primers specific for the unmethylated allele. Lane $M$, DNA marker; $N$, normal control tissue; $T$, intraductal papillary neoplasm; $R K O$, positive control colon cancer cell line.

garding their molecular pathogenesis. Although the histologic and clinicopathologic features of those biliary papillary neoplasms that clinicopathologically resemble pancreatic IPMNs have been described in clinical case reports and several series (2-19, 22-25), their genetic alterations have only rarely been investigated $(11,20)$. One case of biliary papillomatosis was shown to carry an activating mutation of the $K$-ras oncogene (11), but we recently found only relatively infrequent $K$-ras mutations, relatively infrequent allelic losses on chromosomes $5 \mathrm{q}$ and $18 \mathrm{q}$, and no evidence for $\mathrm{p} 53 /$ chromosome $17 \mathrm{p}$ alterations in biliary IPNs (20). During these investigations we observed several neoplasms with shifts in microsatellite markers during allelic loss analysis, a finding suggesting that
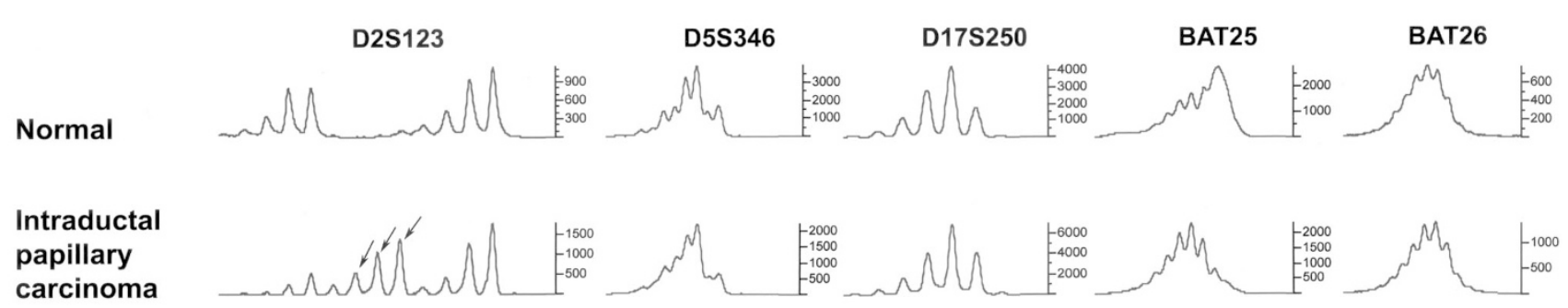

FIGURE 3. Low-level microsatellite instability in Case B2. Allelic shift in this intraductal papillary carcinoma is seen only in D2S123 (arrows). 
microsatellite instability might play a role in the pathogenesis of a subset of these tumors.

The results of this study using the NCIrecommended investigation of microsatellite instability indicate that MSI is relatively common in biliary papillary neoplasms $(47 \%$, including highlevel MSI in $11.8 \%$ and low-level MSI in 35.3\%) and does not depend on the intra- or extrahepatic location of the neoplasm in the biliary tree. Interestingly, there is also evidence for clonal heterogeneity in the development of invasive cholangiocarcinomas from intraductal biliary papillary precursor lesions. Our series included 5 intraductal biliary papillary neoplasms and their associated cholangiocarcinomas that demonstrated MSI (high-level MSI in 1 case and lowlevel MSI in 4 cases); in 3 of these cases, the intraductal and invasive components of the neoplasms showed differing amplicon sizes in the shifted microsatellite loci, and in one case with high-level MSI, the invasive component showed shifting of one additional locus (Bat-25) that was not present in the intraductal component.

The frequency of MSI in these biliary papillary neoplasms is therefore somewhat higher than that reported for other neoplasms derived from (nonampullary) biliary epithelium. Among gallbladder carcinomas, MSI was detected in 0 of 22 (0\%) carcinomas by Saetta et al. (33); in 3 of 15 (20\%) carcinomas by Kim et al. (34); in 5 of 30 (17\%) carcinomas by Yoshida et al. (35); and "widespread" MSI, in only 1 of 32 carcinomas by Chang et al. (36). Among cholangiocarcinomas, MSI was detected in 5 of 38 (13\%) extrahepatic cholangiocarcinomas by Suto et al. (37), in 4 of 22 (18\%) intrahepatic cholangiocarcinomas by Momoi et al. (38), and in 3 of 18 (17\%) intrahepatic cholangiocarcinomas by Kawaki et al. (39). In addition, MSI was absent from multiple samples of the preneoplastic biliary epithelium of the intra- and extrahepatic biliary tree in 21 patients with primary sclerosing cholangitis (40). Only biliary tract carcinomas arising in association with pancreaticobiliary maljunction have been reported to show more frequent MSI; MSI was present in 16 of $23(70 \%)$ such tumors (including 9 of 15 gallbladder carcinomas and 7 of 8 bile duct carcinomas) in the study by Nagai et al. (41). Of note, reliable comparison between studies is difficult because most investigations of MSI in biliaryderived neoplasms have not employed the NCIrecommended loci and because frequently any shifted locus is taken as evidence for MSI. For example, among all of the studies cited above, highlevel MSI was present in only 1 of 32 gallbladder carcinomas (36) and in 4 of 22 intrahepatic cholangiocarcinomas (38), using a criterion of shifting in $\geq 40 \%$ of microsatellite loci examined.
The biliary papillary neoplasms studied here constitute a distinct subset of biliary tumors. It has become increasingly recognized that tumors such as these resemble pancreatic IPMNs in some of their clinicopathologic features $(2,19,21,22)$. Histologically, like pancreatic IPMNs they are comprised of a predominant intraductal growth of papillary fronds with fine vascular cores. Although the degree of extracellular mucin production may not always be as extensive as that found in most pancreatic IPMNs (22), like IPMNs they are comprised of a neoplastic proliferation of epithelial cells with varying biliary, foveolar, or intestinal differentiation and showing varying degrees of epithelial dysplasia. Both biliary and pancreatic tumors can spread extensively along a dilated duct system (as was the case for 15 biliary lesions studied here) or can constitute localized, solitary growths within a dilated duct ( 2 of the lesions in this study). Both the biliary and pancreatic intraductal components can serve as the precursor lesions for invasive carcinomas (invasive cholangiocarcinomas or pancreatic ductal adenocarcinomas, respectively), but even in the absence of invasion, both lesions can cause significant morbidity and mortality because of obstruction of the excretory ducts $(4,6,7,19,23-25)$. It would therefore be of interest to compare the frequency of MSI in these two distinctive neoplasms. However, despite otherwise relatively numerous studies of the immunohistochemical and molecular genetic alterations in pancreatic IPMNs (42-50), we are not aware of any published investigation of MSI in pancreatic IPMNs.

Although a replication-error phenotype is known to occur with varying frequencies among the neoplasms arising in many different organ systems, the mechanism of MSI has been most thoroughly elucidated in colorectal, gastric, and endometrial adenocarcinomas. In sporadic colorectal carcinomas, high-level MSI is observed in approximately $15 \%$ of cases, particularly right-sided lesions, and the majority of such tumors show epigenetic hypermethylation of $\mathrm{CpG}$ islands in the $h M L H 1$ promotor, one of the key genes involved in DNA mismatch repair (51-54). In sporadic gastric adenocarcinomas, hypermethylation of the $h M L H 1$ promoter is present in the majority of MSI-H tumors (55-61), but neither $h M L H 1$ gene mutations (57) nor alterations of $h M S H 2$ are found $(56,57)$ (although several sporadic gastric carcinomas with $h M S H 6$ mutations have been reported) (62). Some investigators also report $h M L H 1$ methylation in gastric carcinomas with low-level MSI, although less frequently than in high- level MSI cases $(56,58,59)$. Approximately one quarter of sporadic endometrial carcinomas are MSI-H, and in the majority of cases the replication-error phenotype is again associated with epigenetic hypermethylation of the 
hMLH1 promoter rather than with $h M L H 1$ or hMSH2 gene mutations (63).

In contrast, the mechanism of (less frequently observed) MSI in biliary-derived neoplasms, including invasive cholangiocarcinomas and gallbladder adenocarcinomas has only rarely been investigated. In a series of extrahepatic biliary carcinomas, Suto et al. (37) found loss of heterozygosity at the $h M L H 1$ and $h M S H 2$ gene loci in only $4 \%$ and $6.1 \%$ of cases, respectively. In a series of biliary carcinomas associated with pancreaticobiliary maljunction and displaying more frequent MSI, Nagai et al. (41) found loss of heterozygosity at the $h M L H 1$ and $h M S H 2$ loci in $12.5 \%$ and $25 \%$. However, the methylation status of the $h M L H 1$ promoter in these tumors has not previously been investigated. The results of this study suggest that microsatellite instability plays a role in the pathogenesis of a subset of intraductal biliary papillary neoplasms, a clinicopathologically distinctive neoplasm among biliary tumors, but no evidence for $h M L H 1$ hypermethylation was found.

\section{REFERENCES}

1. Nakanuma Y, Sripa B, Vantanasapt V, Leong AS-Y, Ponchon $\mathrm{T}$, Ishak KG. Intrahepatic cholangiocarcinoma. In: Hamilton SR, Aaltonen LA, editors. World Health Organization classification of tumours. Pathology and genetics. Tumors of the digestive system. Lyon, France: YHIARC Press; 2000. p. 17380.

2. Albores-Saavedra J, Henson DE, Klimstra DS. Benign epithelial tumors and papillomatosis of the extrahepatic bile ducts. In: Albores-Saavedra J, Henson DE, Klimstra DS, editors. Atlas of tumor pathology. Tumors of the gallbladder, extrahepatic bile ducts, and ampulla of Vater. 3rd series, Fascicle 27. Washington, DC: Armed Forces Institute of Pathology; 2000. p. $171-80$.

3. Baillie J. Tumors of the gallbladder and bile ducts. J Clin Gastroenterol 1999;29:14-21.

4. Bronnimann S, Zimmermann A, Baer HU. Diffuse bile duct papillomatosis: high rate of recurrence and risk of malignant transformation. Chirurg 1996;67:93-7.

5. Callea F, Sergi C, Fabbretti G, Brisigotti M, Cozzutto C, Medicina D. Precancerous lesions of the biliary tree. J Surg Oncol Suppl 1993;3:131-3.

6. Cheng MS, AhChong AK, Mak KL, Yip AW. Case report: two cases of biliary papillomatosis with unusual associations. J Gastroenterol Hepatol 1999;14:464-7.

7. Colombari R, Tsui W. Biliary tumors of the liver. Semin Liver Dis $1995 ; 15: 402-13$.

8. Gertsch P, Thomas P, Baer H, Lerut J, Zimmerman A, Blumgart LH. Multiple tumors of the biliary tract. Am J Surg 1990;159:386-8.

9. Hubens G, Delvaux G, Willems G, Bourgain C, Kloppel G. Papillomatosis of the intra- and extrahepatic bile ducts with involvement of the pancreatic duct. Hepatogastroenterology 1991;38:413-8.

10. Kim YS, Myung SJ, Kim SY, Kim HJ, Kim JS, Park ET, et al. Biliary papillomatosis: clinical, cholangiographic and cholangioscopic findings. Endoscopy 1998;30:763-7.

11. Ohta H, Yamaguchi Y, Yamakawa O, Watanabe H, Satomura $\mathrm{Y}$, Motoo Y, et al. Biliary papillomatosis with the point mutation of K-ras gene arising in congenital choledochal cyst. Gastroenterology 1993;105:1209-12.
12. Sagar PM, Omar M, Macrie J. Extrahepatic biliary papillomatosis occurring after removal of a dysplastic gallbladder. HPB Surg 1993;6:219-21.

13. Seo DW, Lee SK, Kim MH. Biliary papillomatosis. Gastrointest Endosc 2000;51:67.

14. Taguchi J, Yasunaga M, Kojiro M, Arita T, Nakayama T, Simokobe T. Intrahepatic and extrahepatic biliary papillomatosis. Arch Pathol Lab Med 1993;117:944-7.

15. Terada T, Mitsui T, Nakanuma Y, Miura S, Toya D. Intrahepatic biliary papillomatosis arising in nonobstructive intrahepatic biliary dilatations confined to the hepatic left lobe. Am J Gastroenterol 1991;86:1523-6.

16. Tireli M, Uslu A. Multiple biliary papillomatosis. HPB Surg 1992;6:125-7.

17. Loh A, Kamar S, Dickson GH. Solitary benign papilloma (papillary adenoma) of the cystic duct: a rare cause of biliary colic. Br J Clin Pract 1994;48:167-8.

18. Chae BW, Chung JP, Park YN, Yoon DS, Yu JS, Lee SJ, et al. Villous adenoma of the bile ducts: a cases report and a review of the reported cases in Korea. Yonsei Med J 1999;40: $84-9$.

19. Kim HJ, Kim MH, Lee SK, Yoo KS, Park ET, Lim BC, et al. Mucin-hypersecreting bile duct tumor characterized by a striking homology with an intraductal papillary mucinous tumor (IPMT) of the pancreas. Endoscopy 2000;32:389-93.

20. Lee J-H, Furth EE, Wu TT, Abraham SC. Intraductal papillary neoplasms of the biliary tree: molecular and immunohistochemical analysis [abstract]. Mod Pathol 2001;14:199A.

21. Chen T-C, Nakanuma Y, Zen Y, Chen M-F, Jan Y-Y, Yeh T-S, et al. Intraductal papillary neoplasia of the liver associated with hepatolithiasis. Hepatology 2001;34:651-8.

22. Shimonishi T, Zen Y, Chen T-C, Chen M-F, Jan Y-Y, Yeh T-S, et al. Increasing expression of gastrointestinal phenotypes and p53 along with histologic progression of intraductal papillary neoplasia of the liver. Hum Pathol 2002;33:503-11.

23. Adolphs HD, Schlachetzki J, Breining H, Karhoff B. Malignant papillomatosis of the extrahepatic bile ducts. Med Klin 1974;69:1899-902.

24. Helpap B. Malignant papillomatosis of the intrahepatic bile ducts. Acta Hepatogastroenterol 1977;24:419-25.

25. Neumann RD, LiVolsi VA, Rosenthal NS, Burrell M, Ball TJ. Adenocarcinoma in biliary papillomatosis. Gastroenterology 1976;70:779-82.

26. Boland CR, Thibodeau SN, Hamilton SR, Sidransky D, Eshleman JR, Burt RW, et al. A National Cancer Institute Workshop on Microsatellite Instability for cancer detection and familial predisposition: development of international criteria for the determination of microsatellite instability in colorectal cancer. Cancer Res 1998;58:5248-57.

27. Solcia E, Capella C, Kloppel G. Tumors of the exocrine pancreas. In: Solcia E, Capella C, Kloppel G, editors. Atlas of tumor pathology. Tumors of the pancreas. 3rd series, Fascicle 20. Washington, DC: Armed Forces Institute of Pathology; 1997. p. 31-144.

28. Kloppel G, Solcia E, Longnecker DS, Capella C, Sobin LH. Histologic typing of tumours of the exocrine pancreas. New York: Springer-Verlag; 1996.

29. Adsay NV, Longnecker DS, Klimstra DS. Pancreatic tumors with cystic dilatation of the ducts: intraductal papillary mucinous neoplasms and intraductal oncocytic papillary neoplasms. Semin Diagn Pathol 2000;17:16-30.

30. Moskaluk CA, Kern SE. Microdissection and polymerase chain reaction amplification of genomic DNA from histological tissue sections. Am J Pathol 1997;150:1547-52.

31. Berg KD, Glaser CL, Thompson RE, Hamilton SR, Griffin CA, Eshleman JR. Detection of microsatellite instability by fluorescence multiplex polymerase chain reaction. J Mol Diagn 2000;2:20-8. 
32. Herman JG, Graff JR, Myohanen S, Nelkin BD, Baylin SB. Methylation-specific PCR. a novel PCR assay for methylation status of CpG islands. Proc Natl Acad Sci U S A 1996;93: 9821-6.

33. Saetta A, Lazaris AC, Michalopoulos NV, Davaris PS. Genetic alterations involved in the development of gallbladder carcinomas from Greek patients. Hepatogastroenterology 2001; 48:1284-8.

34. Kim Y-T, Kim J, Jang YH, Lee WJ, Ryu JK, Park Y-K, et al. Genetic alterations in gallbladder adenoma, dysplasia and carcinoma. Cancer Lett 2001;169:59-68.

35. Yoshida T, Sugai T, Habano W, Nakamura S, Uesugi N, Funato $\mathrm{O}$, et al. Microsatellite instability in gallbladder carcinoma: two independent genetic pathways of gallbladder carcinogenesis. J Gastroenterol 2000;35:768-74.

36. Chang HJ, Kim SW, Kim YT, Kim WH. Loss of heterozygosity in dysplasia and carcinoma of the gallbladder. Mod Pathol 1999;12:763-9.

37. Suto T, Habano W, Sugai T, Uesugi N, Kanno S, Saito K, et al. Infrequent microsatellite instability in biliary tract cancer. J Surg Oncol 2001;76:121-6.

38. Momoi H, Itoh T, Nozaki Y, Arima Y, Okabe H, Satoh S, et al. Microsatellite instability and alternative genetic pathway in intrahepatic cholangiocarcinoma. J Hepatol 2001;35:235-44.

39. Kawaki J, Miyazaki M, Ito H, Nakagawa K, Shimizu H, Yoshidome $\mathrm{H}$, et al. Allelic loss in human intrahepatic cholangiocarcinoma: correlation between chromosome $8 \mathrm{p} 22$ and tumor progression. Int J Cancer 2000;88:228-31.

40. Jin SY, Noffsinger AE, Bejarano P, Weber FL Jr, Hanto DW, Belli JM, et al. Microsatellite instability is absent in liver and biliary mucosa of patients with primary sclerosing cholangitis. Dig Dis Sci 1999;44:595-601.

41. Nagai M, Kawarada Y, Watanabe M, Iwase T, Muneyuki T, Yamao K, et al. Analysis of microsatellite instability, TGF-beta type II receptor gene mutations and hMSH2 and hMLH1 allele losses in pancreaticobiliary maljunction-associated biliary tract tumors. Anticancer Res 1999;19:1765-8.

42. Fujii H, Inagaki M, Kasai S, Miyokawa N, Tokusashi Y, Gabrielson E, et al. Genetic progression and heterogeneity in intraductal papillary-mucinous neoplasms of the pancreas. Am J Pathol 1997;151:1447-54.

43. Iacobuzio-Donahue CA, Klimstra DS, Adsay NV, Wilentz RE, Argani P, Sohn TA, et al. Dpc-4 protein is expressed in virtually all human intraductal papillary mucinous neoplasms of the pancreas: comparison with conventional ductal adenocarcinomas. Am J Pathol 2000;157:755-61.

44. Islam HK, Fujioka Y, Tomidokoro T, Sugiura H, Takahashi T, Kondo S, et al. Immunohistochemical analysis of expression of molecular biologic factors in intraductal papillarymucinous tumors of pancreas-diagnostic and biologic significance. Hepatogastroenterology 1999;46:2599-605.

45. Luttges J, Zamboni G, Longnecker D, Kloppel G. The immunohistochemical mucin expression pattern distinguishes different types of intraductal papillary mucinous neoplasms of the pancreas and determines their relationship to mucinous noncystic carcinoma and ductal adenocarcinoma. Am J Surg Pathol 2001;25:942-8.

46. Sakai Y, Yanagisawa A, Shimada M, Hidaka E, Seki M, Tada $\mathrm{Y}$, et al. K-ras gene mutations and loss of heterozygosity at the p53 gene locus relative to histological characteristics of mucin-producing tumors of the pancreas. Hum Pathol 2000; 31:795-803.

47. Satoh K, Shimosegawa T, Moriizumi S, Koizumi M, Toyota T. $\mathrm{K}$-ras mutation and p53 protein accumulation in intraductal mucin-hypersecreting neoplasms of the pancreas. Pancreas 1996;12:362-8.

48. Sessa F, Solcia E, Capella C, Bonato M, Scarpa A, Zamboni G, et al. Intraductal papillary-mucinous tumours represent a distinct group of pancreatic neoplasms: an investigation of tumour cell differentiation and K-ras, p53, and c- erbB-2 abnormalities in 26 patients. Virchows Arch 1994;425:35767.

49. Tada M, Omata M, Ohto M. Ras gene mutations in intraductal papillary neoplasms of the pancreas. Analysis in five cases. Cancer 1991;67:634-7.

50. Z'graggen K, Rivera JA, Compton CC, Pins M, Werner J, Fernandez-del Castillo C, et al. Prevalence of activating K-ras mutations in the evolutionary stages of neoplasia in intraductal papillary mucinous tumors of the pancreas. Ann Surg 1997;226:491-8.

51. Cunningham JM, Christensen ER, Tester DJ, Kim CY, Roche PC, Burgart LJ, et al. Hypermethylation of the hMLH1 promoter in colon cancer with microsatellite instability. Cancer Res 1998;58:3455-60.

52. Atkin NB. Microsatellite instability. Cytogenet Cell Genet 2001;92:177-81.

53. Miyakura Y, Sugano K, Konishi F, Ichikawa A, Maekawa M, Shitoh K, et al. Extensive methylation of hMLH1 promoter region predominates in proximal colon cancer with microsatellite instability. Gastroenterology 2001;121:1300-9.

54. Young J, Simms LA, Biden KG, Wynter C, Whitehall V, Karamatic R, et al. Features of colorectal cancers with high-level microsatellite instability occurring in familial and sporadic settings: parallel pathways of tumorigenesis. Am J Pathol 2001;159:2107-16.

55. Leung SY, Yuen ST, Chung LP, Chu KM, Chan AS, Ho JC. hMLH1 promoter methylation and lack of hMLH1 expression in sporadic gastric carcinomas with high-frequency microsatellite instability. Cancer Res 1999;59:159-64.

56. Jung HY, Jung KC, Shim YH, Ro JY, Kang GH. Methylation of the hMLH1 promoter in multiple gastric carcinomas with microsatellite instability. Pathol Int 2001;51:445-51.

57. Bevilacqua RA, Simpson AJ. Methylation of the hMLH1 promoter but no hMLH1 mutations in sporadic gastric carcinomas with high-level microsatellite instability. Int J Cancer 2000;87:200-3.

58. Fleisher AS, Esteller M, Wang S, Tamura G, Suzuki H, Yin J, et al. Hypermethylation of the hMLH1 gene promoter in human gastric cancers with microsatellite instability. Cancer Res 1999;59:1090-5.

59. Fleisher AS, Esteller M, Tamura G, Rashid A, Stine OC, Yin J, et al. Hypermethylation of the hMLH1 gene promoter is associated with microsatellite instability in early human gastric neoplasia. Oncogene 2001;20:329-35.

60. Endoh Y, Tamura G, Ajioka Y, Watanabe H, Motoyama T. Frequent hypermethylation of the hMLH1 gene promoter in differentiated-type tumors of the stomach with the gastric foveolar phenotype. Am J Pathol 2000;157:717-22.

61. Toyota M, Ahuja N, Suzuki H, Itoh F, Ohe-Toyota M, Imai K, et al. Aberrant methylation in gastric cancer associated with the CpG island methylator phenotype. Cancer Res 1999;59: 5438-42.

62. Imai Y, Inoue T, Ishikawa T. Mutations of the MUT S homologue 6 gene in ampullary carcinoma and gastric cancer. Int J Cancer 1998;78:576-80.

63. Gurin CC, Federici MG, Kang L, Boyd J. Causes and consequences of microsatellite instability in endometrial carcinoma. Cancer Res 1999;59:462-6. 